\title{
CORRIGENDUM
}

\section{Two tales of one city: data, inference and Carthaginian infant sacrifice- CORRIGENDUM}

\author{
J.H. Schwartz, F.D. Houghton, L. Bondioli \& R. Macchiarelli
}

Published by Cambridge University Press, 4 April 2017.

We wish to correct the following errors that have been brought to our attention in a paper published in the April 2017 issue, written by J.H. Schwartz, F.D. Houghton, L. Bondioli and R. Macchiarelli: Two tales of one city: data, inference and Carthaginian infant sacrifice. Antiquity 91: 442-54; the following page numbers refer to that article.

1) p. 447 "Our age estimates (pace Smith et al. 2013) did not derive primarily from measurement of the petrosal bone and an inappropriate combination of its length and width.”

Smith et al. (2013) made reference in their critique not just to the petrosal bone but to the cranial bones in general.

2) p. 447 "Although Smith et al. (2013) cited Krogman (1949) as demonstrating marked heat-induced shrinkage [. . .]"

Smith et al. (2013) did not quote Krogman (1949) on this issue, and Krogman (1949) is not included in the references to that paper.

3) p. 448 "They also claimed (Smith et al. 2011, 2013) that both Shipman et al. (1984) and Buikstra and Swegle (1989) demonstrated heat-induced crown shrinkage."

Buikstra and Swegle (1989) were not cited in either Smith et al. (2011) or Smith et al. (2013). Shipman et al. (1984) was only cited in relation to colour change and changes in the microstructure of enamel, not to heat-induced crown shrinkage.

4) p. 448 "any effect heat might have on tooth size can be determined only by measuring the same teeth, pre- and post cremation as Deutsch and colleagues (Deutsch \& Shapira 1987 [. . .]) and Soleil et al. (1958) did." 


\section{Corrigendum}

Neither Deutsch and Shapiro (1987) nor Soleil et al. (1958) measured the same teeth preand post-cremation.

5) p. 448, caption to Figure 2B: "Carthage Tophet molar (left) and an uncremated molar (right), which Smith et al. (2013) correctly identified as being at the same developmental age, thereby demonstrating that heat does not affect tooth morphology or relative states of development".

Figure 2B is reproduced from Smith et al.'s (2013) Figure 2, but the caption to the latter figure refers to the illustrated teeth "showing differences in surface anatomy and loss of cervical enamel in the cremated specimen", not to shrinkage or crown height.

6) p. 448, caption to Figure 2D: "the dark band delineates the dentino-enamel juncture, which Smith et al. (2011) misidentified as a neonatal line”.

In none of the images in Smith et al. (2011) did the authors delineate a neonatal line.

\section{Full citation}

Schwartz, J., F. Houghton, L. Bondioli \& R. Macchiarelli. 2017. Two tales of one city: data, inference and Carthaginian infant sacrifice. Antiquity 91: 442-54. https://doi.org/10.15184/aqy.2016.270 